\title{
Cultural and environmental factors of triple-negative breast carcinomas
}

\author{
Mackenzie Whitesell ${ }^{1}$, Sarah Al-Najar², Gillian Bowser ${ }^{3,4}$, Mark A. Brown ${ }^{4,5,6, ~ * ~}$ \\ ${ }^{1}$ Department of Environmental and Radiological Health Sciences, Colorado State University, Fort Collins, USA \\ ${ }^{2}$ Department of Biomedical Sciences, Colorado State University, Fort Collins, USA \\ ${ }^{3}$ Natural Resource Ecology Laboratory, Colorado State University, Fort Collins, USA \\ ${ }^{4}$ Department of Ethnic Studies, Colorado State University, Fort Collins, USA \\ ${ }^{5}$ Department of Clinical Sciences, Colorado State University, Fort Collins, USA \\ ${ }^{6}$ Colorado School of Public Health, Colorado State University, Fort Collins, USA
}

Email address:

M.Brown@colostate.edu (M. A. Brown)

To cite this article:

Mackenzie Whitesell, Sarah Al-Najar, Gillian Bowser, Mark A. Brown. Cultural and Environmental Factors of Triple-Negative Breast Carcinomas. Cancer Research Journal. Vol. 2, No. 2, 2014, pp. 18-28. doi: 10.11648/j.crj.20140202.12

\begin{abstract}
Breast cancer is a leading cause of cancer death in the world. The triple-negative breast cancer subtype is associated with poorer prognosis than hormone receptor-positive subtypes and is more prevalent among African Americans than white, European Americans. The goal of this study has been to elucidate environmental, hormonal, and cultural factors that may be contributing to this disparity in an effort to identify modifiable risk factors and improve triple-negative breast cancer outcomes. Factors that may impact risk include vitamin D defiency, hormonal factors, environmental and dietary exposure, radiation exposure, and obesity. These factors may disproportionately affect African American women as a result of socioeconomic status, lifestyle, and cultural norms. Furthermore, disparities in prognosis may be compounded by barriers such as access to healthcare, prevention education, and perceptions of healthcare. Both biological and sociocultural factors impacting risk must be addressed in order for future prevention and treatment efforts to succeed.
\end{abstract}

Keywords: Health Disparity, Triple-negative Breast Cancer, Cultural Factors, Environmental Factors

\section{Introduction}

Cancer is an issue of growing concern, with 12.7 million new cases occurring in 2008 alone [1]. Among cancer mortalities, breast cancer is the second leading cause of deaths among women in the United States [2]. Though white American women have higher rates of breast cancer incidence than African American women, the latter population is more likely to die from breast cancer than any other ethnic group in the United States [3-6] .

In many cases, the difference in survival is linked to variation in cancer subtypes between ethnic groups. Specifically, African American women have a higher incidence of triple-negative breast cancer than White Americans [7-11]. Triple-negative breast cancer is one of five subtypes of breast cancer which have been recognized to be luminal A (ER+ or PR+, HER2 -), luminal B (ER+ or PR+, HER2 +), HER2-overexpressing (ER-, PR-, HER-2+), basal-like (ER-, PR-, HER-2-, cytokeratin 5/6 + or epidermal growth factor receptor + ), and unclassified or normal tumors [10-12]. The latter two subtypes, basal-like and normal, are oftentimes combined into the subtype known as triple-negative breast cancer $[9,10]$.

However, there is some ambiguity in the literature regarding the classification of subtypes. It is important to note that "basal-like" and "triple-negative" are not exactly synonymous (though they oftentimes overlap), as basal-like refers primarily to tumors defined by gene expression markers (including cytokeratins), whereas triple-negative is defined as having ER-, PR-, and HER2- status [7, 9]. The triple-negative subtype is commonly referred to in the literature and will be the primary focus of this review.

The triple-negative phenotype is associated with higher mortality than hormone receptor positive subtypes (luminal $\mathrm{A}$ and luminal B) [7, 10, 12-15]. This is linked to the fact that triple-negatives are inherently more aggressive and because they have poorer response to current breast cancer treatments for the clinical management of breast cancer [13].

The purpose of this review is to address disparities in 
African American and White American breast cancer mortality through exploration of environmental and hormonal risk factors for triple-negative breast cancer, as well as sociocultural factors that may contribute to increased breast cancer mortality among African Americans. Though triple-negative status is likely a large contributor to high mortality rates, all risk factors for African American breast cancer mortality may not be mediated through the tumor phenotype. Other compounding factors are linked to socioeconomic status, cultural beliefs, healthcare access, and discrimination within the healthcare system. These factors will also be discussed in an effort to provide a holistic review of potentially modifiable risk factors among African American women.

There is a body of research that has explored inherited genetic proclivity towards the triple-negative phenotype, which indicates a role of BRCA1 and BRCA2 gene mutations in African American women [4, 9, 16-18]. However, it is clear that risk is not entirely genetic and this review seeks to elucidate non-inherited risk factors (which are therefore modifiable) and will not discuss genetic proclivity in depth.

The modifiable risk factors for breast cancer in African American women that will be discussed are vitamin D, hormonal factors (endogenous and exogenous), environmental exposures, obesity, alcohol, socioeconomic status, and sociocultural factors. Though each will be discussed at length in separate sections, it is important to recognize the connections between the distinct factors and consider risk holistically rather than through the narrow lens of each individual factor.

\section{Vitamin D}

Vitamin D is a prevalent factor in the literature regarding cancer which cannot be ignored when assessing risk for breast cancer among women of African heritage. Measurement of vitamin D's active metabolite $1,25(\mathrm{OH})_{2} \mathrm{D}$ is difficult due to the compound's short half-life. Thus, its more stable precursor, $25(\mathrm{OH}) \mathrm{D}$, is used to measure serum concentrations of vitamin D [19-23]. Higher serum $25(\mathrm{OH}) \mathrm{D}$ levels have been associated with decreased risk for breast cancer [19-21]. The strongest association has been reported to be among post-menopausal women [21]. Inverse relationships have also been found between vitamin $\mathrm{D}$ levels and mammographic density, which is a factor indicative of breast cancer risk [18, 24]. There is some evidence, however, that increasing supplementation of vitamin D and calcium may not have a significant impact on decreasing mammographic density [25].

The mechanism through which vitamin $\mathrm{D}$ reduces risk of breast cancer is not fully understood. However, it has been proposed that one mechanism may be through the increased production of e-cadherin glycoprotein in mammary epithelial cells via the binding of $1,25(\mathrm{OH})_{2} \mathrm{D}$ (vitamin D's active metabolite) to the vitamin D receptor (VDR) [20]. Other possible mechanisms of vitamin $\mathrm{D}$ include increased apoptosis, prevention of proliferation of tumors, and inhibition of carcinogenesis mediated through the VDR, which is responsible for regulating transcription of genes to code for enzymes associated with cell cycle functioning [22, $23,26,27]$. One possible pathway of increasing apoptosis among cancer cells is via down-regulation of insulin-like growth factor I (IGF-I) by the vitamin D analogue EB1089 $[22,26]$. IGF-I is a mitogen which hinders apoptosis of cancer cells and thus inhibition of IGF-I by EB1089 can up-regulate apoptosis [22, 26].

Decreased risk of ER-positive breast cancers may be linked to down-regulation of aromatase, which is necessary for synthesis of estrogens [20]. However, it is unlikely that this is the only mechanism, as ER-negative tumors have also been shown to be affected by vitamin $\mathrm{D}$, with one study finding that for every $10 \mathrm{ng} / \mathrm{mL}$ increase of serum $25(\mathrm{OH}) \mathrm{D}$ concentration, the risk of triple-negative breast cancer decreased $64 \%$ [8]. Further studies must be undertaken to elucidate the specific pathways through which vitamin D impacts breast cancer risk for each specific subtype.

Regardless of the mechanisms, however, the inverse relationship between vitamin $\mathrm{D}$ and breast cancer risk requires examination of vitamin D-deficient populations in order determine the direction of public health policy and prevention recommendations among clinicians. In the United States, notable disparities in vitamin D have been found between populations of differing skin color. It has been consistently reported that serum $25(\mathrm{OH}) \mathrm{D}$ levels are lower among African Americans when compared to white Americans [23, 28-30]. In the United States, $21 \%$ to $45 \%$ of African Americans have been reported to be Vitamin D deficient ([serum 25(OH)D] $<10 \mathrm{ng} / \mathrm{mL}$ and $<15 \mathrm{ng} / \mathrm{mL}$, respectively) [28, 29]. In contrast, it has been found that only $11 \%$ of white Americans have serum 25(OH)D concentrations $<15 \mathrm{ng} / \mathrm{mL}$ [28].

These disparities in $25(\mathrm{OH}) \mathrm{D}$ serum concentrations may be, in part, attributable to differences in melanin levels between African American and white American individuals. Though specific amounts vary widely depending on geographic location, lifestyle habits, sunscreen use, and skin pigmentation, much of humans' vitamin D comes in the form of cutaneous exposure to the sun, whereby UVB light penetrates the skin thereby synthesizing vitamin D metabolites [8, 20, 31]. High levels of melanin content in skin block UVB rays, which protect against UVB-associated skin carcinomas, but can also contribute to hypovitaminosis D [31]. Women of African ancestry have high melanin content in their skin, which is advantageous in equatorial and tropical areas where direct sunlight is prevalent and does not typically hinder serum 25(OH)D levels [29, 32]. However, for individuals of African ancestry who live in the more northern latitudes of North America, inadequate sun exposure can decrease vitamin D levels [8, 29]. It has been postulated that the historical forced migration of Africans to North America may account for the lack of adaptations of melanin concentrations to less direct sun light [8, 27].

Another factor that may be contributing to decreased 
serum 25(OH)D levels among African Americans is obesity [20, 23, 27, 28, 33]. Body mass index (BMI) measurements have been found to be inversely correlated with serum $25(\mathrm{OH}) \mathrm{D}$ levels $[23,30]$. High BMI has also been found to be a strong predictor of low vitamin D levels among African American women specifically, with one study reporting over a six-fold increase in risk for hypovitaminosis D among obese women of African descent in the southeastern United States compared to non-obese women [28]. African Americans have higher prevalence of obesity than white Americans, with recent data reporting obesity prevalence in the United States to be $49.5 \%$ among the non-Hispanic black population compared to $39.3 \%$ among the non-Hispanic white population [34].

This disparity in obesity prevalence may be contributing to increased vitamin D deficiency among African Americans when compared to white Americans. However, there is also some evidence that the association of obesity with vitamin D is stronger among post-menopausal women, whereas African American women are more at risk for pre-menopausal breast cancer (often triple-negative or basal type) compared to their white counterparts [20]. Obesity is also a risk factor for breast cancer, and the triple-negative subtype specifically, independent of its effect on vitamin D availability. This will be discussed in detail further on.

The mechanism through which obesity is associated with serum $25(\mathrm{OH}) \mathrm{D}$ concentrations may be a result of the hydrophobicity of vitamin D [8]. Because derivatives of vitamin $\mathrm{D}$ are fat-soluble, they may be stored in adipose tissue, which is more prolific in obese individuals. Consequently, circulating levels may decrease and limit the ability of binding to the vitamin D receptor (VDR), thus inhibiting functionality of vitamin D metabolites.

Furthermore, some data suggest that African American populations consume less milk than white American populations, which may also affect vitamin D levels [28]. There is some speculation in the literature that lactose intolerance, which is common among African American populations, may be contributing to this lower milk consumption and by extension less dietary intake of vitamin D [8]. However, serum 25(OH)D concentrations have been found to be lower among even those African American women who have adequate dietary intake of vitamin D [28]. This may suggest that lactose intolerance and low levels of milk intake, while notable, are not of primary concern when determining directions of future research.

While it is clear that future research needs to explore the specific mechanisms of the functionality of vitamin D metabolites in impacting breast cancer risk, it may be advisable to adjust public health and prevention recommendations based on current knowledge. Several authors have recommended vitamin D supplementation as an inexpensive and safe preventative measure for reducing risk of breast [8, 20, 24, 30]. A recent assessment of the qualification of vitamin D as a causal link to breast cancer per the A.B. Hill criteria concluded that criteria have been met [20]. The assessment noted that in their compilation of
30 studies regarding potential toxicity of supplemental vitamin $\mathrm{D}$, no negative effects were found for up to 10,000 IU/day of vitamin $\mathrm{D}_{3}$ or for serum $25(\mathrm{OH}) \mathrm{D}$ concentrations of up to $100 \mathrm{ng} / \mathrm{mL}$ [20]. Another study predicted that if serum $25(\mathrm{OH}) \mathrm{D}$ concentrations were maintained at 50 $\mathrm{ng} / \mathrm{mL}$ through supplemental intake of 2,000 IU/day in combination with skin exposure to the sun, a $50 \%$ reduction in breast cancer incidence would be observed [19]. A community-based assessment of vitamin D intake through the GrassrootsHealth (GRH) database suggested an even wider range of safe intake, noting that intake of up to 40,000 IU/day of vitamin D would likely not cross the threshold for toxicity [35]. The study also determined that supplemental intake of $9,600 \mathrm{IU} /$ day is necessary for $97.5 \%$ of the population to maintain serum $25(\mathrm{OH}) \mathrm{D}$ concentrations of 40 $\mathrm{ng} / \mathrm{mL}[35]$.

This evidence for safety of vitamin D supplementation may be a basis for increasing recommended vitamin $D$ intake. However, this will not guarantee increases in $25(\mathrm{OH}) \mathrm{D}$ concentrations significant enough to reduce breast cancer risk, as supplemental intake has only been found to be associated with small increases in serum concentrations [28].

Further studies also need to be conducted to assess the relationship of triple-negative breast cancer specifically to vitamin D, as that subtype disproportionately affects African American women.

\section{Hormonal Factors}

Some of the most well-established risk factors for breast cancer are linked to both endogenous and exogenous hormones. The risk associated with endogenous hormones comes in the form of age of menarche and menopause, parity, duration of breastfeeding, and age at first full-term pregnancy $[12,17,36]$. Associations of these factors with hormone receptor positive subtypes (luminal A and luminal B) differ from those with hormone receptor negative phenotypes (HER-2 overexpressing, basal-like, triple-negative) [36]. There is some evidence that the risk associated with hormone-mediated factors is greater for luminal phenotypes than for hormone receptor negative phenotypes [12]. Regardless, the focus here will be on the associations that do exist between hormone-mediated factors and triple-negative phenotypes specifically.

First, possible associations with endogenous hormones will be examined. An inverse association has been found for length of duration of breastfeeding and risk for developing triple-negative breast cancer [11, 12, 15, 37-39]. In several studies, this reduced risk was found among women who breastfed for a duration of greater than four months [11, 12]. One study found that, though African American ethnicity was an independent risk factor, breast feeding had no association with risk for triple-negative breast cancer in African American women specifically [38]. However, possible associations may have been masked by the fact that only $31 \%$ of parous African American women in the study 
breastfed [38]. In another large study of African American women, breastfeeding was found to be a protective factor against hormone receptor-negative phenotypes [37]. Again, breastfeeding was less common among African American women than other ethnicities [37]. This low rate of breast feeding may indicate a cultural distinction between African American populations and populations of other heritage in the United States. Further studies need to be done to assess whether these behaviors do, in fact, have a cultural etiology.

Though nulliparity has been found to increase risk in ER+ breast cancers, there is some conflicting information in the literature regarding the impact of parity on risk for triple-negative breast cancer [36]. Several studies have found that increased parity is associated with increased risk for a triple-negative phenotype [11, 36-38], with one finding that being nulliparous decreased risk 39\% [36]. Another study found that in African American women specifically, higher parity increased risk for hormone receptor-negative phenotypes [37]. However, additional studies have found no association between parity and risk [15], and one study specifically found no association in African American women [38]. Of note, African American women typically have relatively high parity compared with white Americans [11, 37, 38].

Early age at menarche may be associated with several subtypes of breast cancer, and there is some evidence that basal-like phenotypes are also linked to early age of menarche [40]. However, the data in that area is not entirely conclusive, as one study found that the triple-negative phenotype was not associated with age of menarche, though the HER-2 overexpressing phenotype was [12]. While the triple-negative and basal-like phenotypes are not synonymous, both are hormone receptor-negative and thus these findings are contradictory when assessing age of menarche as a hormone-mediated risk factor.

Late age of menopause has been linked with increased risk of luminal breast cancers, but one study found no statistically significant association with triple-negative phenotypes [12]. Similarly, age of first full-term pregnancy has been shown to have no association with the triple-negative phenotype $[12,15]$. Another study found no association between age early age of menarche or late age of menopause and high mammographic density, which is a common predictor of breast cancer risk [41]. The study did find, however, a slight increase in mammographic density among women who gave birth to their first child after age thirty [41]. Future studies with large sample sizes are needed to validate these findings.

In addition to these endogenous hormone-mediated factors, there has been research into the impacts of exogenous hormones on triple-negative breast cancer risk. Specifically, data has accumulated regarding hormone replacement therapy (HRT) and oral contraceptive use. HRT is a common therapy among postmenopausal women and has been linked to increased risk for breast cancer in several studies [41, 42]. Specifically, one study found a $17.6 \%$ increase in mammographic density among women using
HRT [41]. One qualitative study of sisters of women diagnosed with breast cancer found that many women identified HRT as a risk factor and several stopped their therapy after their sister's diagnosis, as it was viewed as a modifiable risk factor [43]. However, HRT may not be a significant factor in triple-negative breast cancers in African American women, as it is more commonly used among white Americans and postmenopausal women [11].

Another key form of exogenous hormone exposure, and estrogen exposure specifically, is oral contraceptive use. One large comparative study found a 2.9-fold increase in triple-negative breast cancers among women who began use of oral contraceptives before age 18 and who, at the time of the study, were ages 45-64 [15]. It is important to note that oral contraceptives in use before these women were age 18 had particularly high synthetic estrogen content [15]. A 2009 study that examined 187 cases of triple-negative breast cancer found a 2.5 -fold increase in risk for triple-negative breast cancer among women who had used oral contraceptives for more than one year [44]. The women in the study were ages $21-45$ and the risk increased with longer duration and more recent oral contraceptive use [44]. This suggests that the estrogen content of even more modern birth controls may be sufficient to increase risk.

The mechanism through which estrogen may contribute to ER-negative breast cancers is not entirely clear. However, some research indicates that estrogen affects non-tumor tissues through promotion of angiogenesis and subsequent stromalization, and increased capacity for recruitment of bone marrow cells $[45,46]$. Specifically, one recent study examined the impact of estrogen on ER-negative cancers and found that estrogen increases action of ER $\alpha$-expressing bone marrow-derived monocytes, which subsequently increases angiogenesis [46]. This is consistent with findings that ER-negative tumors have higher microvessel counts than ER-positive tumors [47]. While there is evidence that angiogenesis linked to breast cancer can be induced by vascular endothelial growth factor (VEGF) [45, 48, 49], VEGF is likely not the primary factor responsible for mediation of estrogen's impact on angiogenesis for ER-negative breast tumors [45, 49].

Estrogen is not the only factor linked to the reproductive cycle that impacts breast cancer risk. One recent study identified iron as a significant player in breast cancer, both in premenopausal and postmenopausal women [49]. In premenopausal women, the study found that low iron levels led to hypoxia in breast tissue, which subsequently increased VEGF and angiogenesis [49]. In postmenopausal women, high iron levels were found to increase oxidative stress, which is linked to DNA damage and increased risk for carcinogenesis [49]. Statistically significant higher mean iron concentrations in hair of breast cancer patients have been found when compared to healthy individuals [50], and one study found high levels of iron in breast tissue of postmenopausal women to be a risk factor for development of cancer [51]. Though there is certainly a need for more research regarding iron's role in breast cancer development, 
and particularly with regard to the triple-negative phenotype, the study is consistent with other recent findings that almost $50 \%$ of gene expression related to iron metabolism has a statistically significant association with risk of breast cancer [52].

\section{Environmental Exposures}

Though a great deal of the literature has focused on hormone-related risk factors for breast cancer, it is also important to recognize potential environmental factors that may also be linked to as much as $60 \%$ of increased risk [17]. One contaminant that has emerged in the literature as being associated with breast cancer risk is cadmium [53-59], with one study finding a two-fold increase in risk among women in the highest versus lowest quartile of urine cadmium level [56]. Another study found a positive association between dietary cadmium intake and risk of breast cancer in postmenopausal women [55]. There is also some evidence of associated increased risk of triple-negative breast cancer specifically [53]. However, an analysis of National Health and Nutrition Examination Survey (NHANES) III data found no association between breast cancer mortality and cadmium exposure [60].

The mechanism through which cadmium may impact breast cancer risk is not yet entirely clear, but it may be linked to down regulation of BRCA-1 expression which subsequently inhibits tumor suppression [53]. Other potential mechanisms include inhibition of apoptosis or DNA repair, increased oxidative stress, or action as a metalloestrogen $[55,57]$.

Though cadmium exposure oftentimes is linked to tobacco, its association with breast cancer risk has been found to be independent of tobacco use [54]. Rather, most exposure likely comes in the form of dietary consumption and exposure from use in fertilizers, sewage processing, and metal processing industries $[54,55]$. There is some evidence that African Americans have higher cadmium exposure, as one study found higher urinary cadmium concentrations among African American men and women than among white Americans and Mexican Americans, though the finding was only statistically significant for African American women compared with women of other ethnic groups [61]. This higher exposure may be linked to differences in occupational exposure as related to socioeconomic status, but further research must be conducted to confirm higher cadmium exposure among African American women and to elucidate differential sources of exposure.

Other trace elements may also have a key role in breast cancer development. There is some evidence that excessive zinc blood concentrations are associated with greater risk for breast cancer [51, 57]. A similar association has been observed for chromium [57], and copper [50, 57]. However, a study of breast cancer patients in Kuwait found significantly lower blood concentrations of zinc and copper among stage I breast cancer patients when compared to controls, though the authors noted that prior studies typically found an increase in blood copper among breast cancer patients [58]. In another study, significantly lower concentrations of zinc in hair were also reported among breast cancer patients than among healthy individuals [50].

There have also been findings that plasma of individuals with breast cancer contains higher levels of manganese, nickel, lead, antimony, and strontium [57].

There is consistent evidence in the literature that high selenium levels are associated with decreased risk for breast cancer [58,62]. There is also some evidence that magnesium and calcium levels are lower in breast cancer patients $[50,57$, 63]. Two studies have found lower levels of these elements in breast cancer patients when compared to health ycontrols $[50,57]$. Another study in Taiwan found an inverse association between levels of magnesium and calcium in drinking water and risk for death as a result of breast cancer [63]. However, one study found a positive association between high levels of calcium and zinc in breast tissue and risk for breast cancer [51].

Based on the incongruity of these studies' results, it is clear that further research needs to be done to clarify the possible associations of these trace metals and to identify the point of balance necessary to preserve the regular cell cycle and homeostasis. There is some evidence that the ratio of trace elements in the body is key for maintaining balance, with one study finding higher ratios of copper/zinc, calcium/magnesium, and copper/iron in breast cancer patients' hair samples than in healthy individuals [50]. It is thought that the balance of trace metals impacts breast cancer risk through effecting oxidative stress [58].

It is important to note that the research into the possible associations between these trace metals and triple-negative breast cancer specifically is limited. It may be necessary to focus studies specifically on each compound's relationship to the various breast cancer phenotypes and with the African American population specifically.

Furthermore, future research related to potentially carcinogenic trace elements may need to be standardized in terms of where the compounds' concentrations are measured (i.e. urinary, plasma, circulating blood, dietary, or breast tissue concentrations). The variation in the literature in terms of forms of measurement may be contributing to ambiguity of associations between element concentrations and risk for breast cancer.

Another key environmental risk factor for breast cancer is ionizing radiation, which is a well-established carcinogen that is thought to function through inhibition of DNA repair pathways [17, 64]. Radiation exposure has been shown to increase risk for ER-negative breast cancers specifically, with risk showing an inverse correlation with age of exposure [64]. Some of this exposure may come in the form of treatment of childhood cancer with radiation, or through occupational exposure, particularly for medical and flight personnel [17, 64].

Other possible environmental risk factors may include occupational exposure to organic solvents and organic 
chlorides (OCs), though more research is needed in these areas [17].

\section{Obesity}

There is a significant amount of evidence in the literature linking obesity and increased BMI with risk for breast cancer [27, 30, 42, 43]. There is also evidence linking obesity to the triple-negative phenotype specifically $[9,39$, 44, 65, 66]. Because African American women are disproportionately affected by obesity, high BMI may be a key mediating factor for disparities in breast cancer outcome between African American and white American women.

As has been discussed, one mechanism through which elevated BMI affects breast cancer risk is through the effects of excess adipose tissue on circulating vitamin D accessibility. Another mediating factor that impacts risk of breast cancer as a result of obesity is hyperinsulinemia [27, 65]. African American populations have particularly high rates of hyperinsulinemia and associated type II diabetes [27]. Hyperinsulinemia has been linked to increased androgen levels, which may subsequently elevate breast cancer risk in premenopausal women [27, 42]. Circulating estrogen levels have also been found to be positively correlated with increasing BMI and breast cancer [42, 66]. This is likely the result of estrogen synthesis that occurs in adipose tissue76.

One study found that mammographic density increased more drastically in response to hormone replacement therapy (HRT) among women whose BMI was greater than 35 , though the finding was not statistically significant [41].

Despite the many mechanisms through which obesity may increase risk for breast cancer, few women, and even fewer African American women specifically, recognize high BMI as a risk for breast cancer [43]. In a study of family members of individuals diagnosed with breast cancer, only $34 \%$ of women indicated that their relative's diagnosis influenced them to alter their habits related to diet and exercise [43]. These findings have implications for public health efforts in that it may be necessary to better educate the public regarding known risk factors for breast cancer.

Furthermore, increasing accessibility of healthy foods and safe means of exercise may be a key factor in decreasing breast cancer risk disparities by socioeconomic status. A 2008 literature review of the prior 25 years found that lack of access to healthy foods and safe locations for physical activity resulting from low socioeconomic status could increase risk for obesity and subsequently increase risk for breast cancer [33].

\section{Socioeconomic Status}

An important factor that may be compounding risk increases for breast cancer mortality among African American women is socioeconomic status (SES) [4, 6, 14, $33,66,69-74]$. The process of disentangling socioeconomic factors from ethnic factors is far from simple, and studies have come to varying conclusions regarding whether or not African American ethnicity is, in fact, a risk factor independent of socioeconomic status.

A 1995 study found that, even after controlling for ethnicity and age, lower socioeconomic status was still associated with higher prevalence of ER-negative tumors [73]. A more recent study on a population of African American and European American individuals, all with lower SES, found that health disparities in triple-negative breast cancer survival are not a result of independent association with African American ethnicity, but rather of differences in quality of care received [70]. Though these two studies examined different variables, both bring to light the reality that African American ethnicity may not be the only factor contributing to increased breast cancer mortality among African American women. Of note, many anthropologists reject the notion of "race" altogether, saying it is nothing more than a social construct, and highlight the potential reality that what is actually being observed when "race" is classified are cultural norms, geographical location, and socioeconomic status [69].

Other factors that are important to address include limited access to care (both geographically and due to insurance limitations), less prevention education, education levels, limited access to healthy food, and less opportunity to exercise, all of which are linked to lower socioeconomic status [33].

Insurance status is an important issue that has been the basis for a great deal of national debate. A large study utilizing data from the National Cancer Database $(\mathrm{n}=$ 193,969 ) found that even after taking ethnic differences into account, uninsured women were 3.66 times more likely to have their cancer metastasize when compared to privately-insured women and were 2.37 times more likely to have a larger tumor [71]. Furthermore, lack of insurance or being underinsured can result in individuals lacking a primary care doctor, which can lead to less prevention education (including lifestyle and breast cancer screening information) and less effective care management [33, 75].

In addition, fewer monetary resources oftentimes equate with less geographical access to care (for example, among those living in rural areas), as well as limited ability to afford transportation to care facilities and restrictions of public transportation [33]. Finally, those living with minimal financial stability oftentimes must prioritize daily necessities (such as food and shelter) over long-term care [33]. While these possible restrictions are certainly logical, more research needs to be conducted to confirm the magnitude of correlation of these factors to breast cancer survival rates.

Lower education level may also contribute to the association between low socioeconomic status and higher breast cancer mortality rates [71, 73]. This association has been found to be mediated by increased prevalence of ER-negative tumors in those with lower education levels [73]. However, more research may need to be done to elucidate the way in which education impacts risk, as such 
an impact may be a result of a combination of increased income/insurance and increased knowledge of prevention and early screening that comes with increased education.

Despite the potential impacts of these compounding factors, it is important to note that there is some evidence that African American ethnicity is itself a risk factor for higher breast cancer mortality. A study that controlled for age, tumor subtype, therapy implementation, and socioeconomic status concluded that African American ethnicity is independently associated with lower breast cancer survival [6]. It is important to recognize that this also indicates that lower survival among African American breast cancer patients may be a result of more than just increased rates of the triple-negative subtype [6]. A similar finding came from a study in Scotland, which concluded that, though rates of ER-negative tumors were higher in economically "deprived" populations as opposed to "affluent" populations ( $52 \%$ versus $35 \%$, respectively), this disparity only partially accounted for the differences in survival between wealthy and impoverished areas [74]. The authors suggested that other factors contributing to the disparity include nutrition, differences in immunology, and comorbidity [74].

\section{Sociocultural Factors}

In addition to biological and socioeconomic risk, African American women may also be at higher risk for breast cancer mortality as a result of cultural and societal factors. Though it is clear that more research needs to be done in this area to elucidate how much impact these factors have on mortality risk, several researchers have recognized potential barriers to health equity that should not be ignored.

One common theme that has emerged in the literature is a lack of knowledge about breast cancer risk among African American women [43, 76]. Many women do not recognize reproductive/hormonal factors, low physical activity, or obesity as risk factors $[43,76]$. Rather, in one study in a rural population of African American women, participants commonly sighted family history, high-fat diets, environmental toxins, and breast damage as the most important risk factors [76].

Furthermore, though most African American women seem to know that mammographic screening exists, there is evidence that many are not getting screened [76, 77]. One study of 320 rural African American women found that only $2 / 3$ of the participants who had a family history of breast cancer had ever had a mammogram [78]. Several common barriers have emerged as preventing women from getting screened lack of knowledge regarding the benefits of early detection, cost of screening, and lack of access to screening in rural areas [76]. Emotional barriers also exist, including fear of painful mammograms, and fear of finding cancer [33, 76, 77]. Qualitative data from focus groups of rural African American women regarding fear of mammography has shown that women are afraid of finding cancer because of fear of death and pain, as well as fear of being a burden to their families and jeopardizing relationships [76, 79]. There is also some evidence that the topic of breast cancer is considered "taboo" in some African American communities, and thus women may be unwilling to talk about prevention and diagnosis of the disease [76].

Of note, in a study of perceptions of mammography, African American women tended to be more skeptical of the benefits of mammography, with $47 \%$ of African American participants holding a "pessimistic" view, while only $15 \%$ of whiteAmerican women held this view [80]. However, the so-called "pessimistic" women tended to also be more accurate about the benefits of mammography, with $39 \%$ of African Americans and only $15 \%$ of white Americans having an accurate perception of its value - most women in the study overestimated the benefits of mammography [80].

There also seems to be a great deal of fear of treatment of breast cancer, as women are worried about the toll that losing their breasts will have on their self-esteem and sexuality [76]. There is also some perception that the treatment of breast cancer is worse than the disease [76, 79, 81]. Much of this fear revolves around surgery, and a common perception in both white American and African American women is that when surgery exposes cancer to the outside environment, it can cause it to spread, thus making the disease worse $[79,81]$.

Furthermore, one of the most significant emotional factors influencing many African American women to not take action regarding breast cancer health is fatalism $[76,77$, 80-82]. Fatalism is defined as the perception that a cancer diagnosis is effectively a "death sentence" - that nothing can be done to stop or prevent the disease [81]. There is evidence that African American women tend to hold fatalistic viewpoints more often than white American women [80, 81]. This fatalism was found to be linked to lower breast cancer screening rates in a study of 71 African American women, as women did not believe that screening would impact what they believed to be their predetermined fate [82].

In addition to these individual beliefs and fears, there is also a notable amount of perceived healthcare discrimination and lack of trust in the healthcare system among African American patients $[33,76,79,83,84]$. In one qualitative study of 280 women and 165 men in Chicago, $97 \%$ of whom were African American, focus group discussions brought to light common mistrust of doctors, largely because of fear of being used for medical experimentation or manipulation by the government [79]. This mistrust has also been found in other studies, and is likely accounted for by a history of experimentation on African American patients in the medical system [33]. Furthermore, many African American patients have a shared perception that their doctors make assumptions about their understanding of disease and thus don't share all of the information regarding their health [79, 83]. One study found that women who thought that doctors withheld information as a result of their race were twice as likely to adhere to a fatalist perspective regarding breast cancer [79].

Because of these perceptions of discrimination, it is clear 
that healthcare providers need to be conscious of their attitude towards patients and make an effort to overcome any internalized assumptions based on a patient's ethnic identity. There is evidence that a positive relationship between a cancer patient and their healthcare provider is crucial in the process of managing the disease [84].

It may be necessary for future studies to look into social and cultural factors that impact risk for triple-negative breast cancer specifically.

\section{Conclusions and Recommendations}

This manuscript has discussed many non-inherited risk factors for breast cancer in African American women. Risk for a triple-negative phenotype specifically has been explored, as the triple-negative subtype is disproportionately high among African American women when compared to white American women and is accompanied by worse prognosis and higher mortality rates. Sociocultural factors were also considered that impact risk for breast cancer mortality in general among African American women. It is clear that a myriad of factors combine to impact risk and that no one contributor can entirely account for increased breast cancer mortality in African American women.

A main goal of this review was to identify modifiable risk factors in hopes of developing strategies to lessen the breast cancer mortality disparity between White and African Americans. Potential modifiable factors that have been discussed include vitamin D, exogenous hormone exposure, breastfeeding, environmental contaminants, and obesity.

The literature regarding vitamin D points to its many potentially protective factors and supports a conclusion that increasing vitamin $\mathrm{D}$ intake may decrease risk for triple-negative breast cancer. Thus, it may be advisable for public health campaigns to be developed that are designed to educate the public, and African American women specifically, regarding the benefits of vitamin D. It may be crucial to advertise the difference in costs between preventative vitamin D supplements and breast cancer treatment and to educate insurance companies so that they may be more inclined to cover costs of vitamins, though such a task is certainly not simple.

Exposure to exogenous hormones that may come in the form of birth control or hormone replacement therapy (HRT) may also be modifiable. Though for many women the protection offered by birth control from unwanted pregnancy may outweigh the risk of breast cancer, continued development of birth control that may include smaller doses of hormones may be effective. Efforts to increase knowledge about the risks of HRT should also continue. One potentially modifiable endogenous hormonal factor is breastfeeding, which is less common in African American women. Since duration of breastfeeding has been found to be inversely associated with risk for triple-negative breast cancer, it is necessary to increase awareness of the benefits of breastfeeding so as to encourage women to breastfeed more often and for longer periods, thus decreasing their risk.
The risk posed by environmental contaminants is less clear. Though elements such as cadmium have been implicated in increasing breast cancer risk among African Americans, many trace metals seem to have an optimal level, above or below which an individual has increased risk for breast cancer or other health problems. Thus, no clear public health recommendation is likely reasonable at this point, but more research is necessary to determine the precise amounts of trace metals that are optimal versus destructive. This knowledge will enable dieticians and environmental health professionals to develop recommendations regarding amount of exposure to and intake of trace metals.

Obesity is a modifiable risk factor that may be the most feasible to target from a public health standpoint, as it is implicated in a myriad of other health concerns, including cardiovascular disease. Because decreasing obesity would decrease risk for many costly diseases (both in terms of human toll and economic cost), funding agencies may be more inclined to devote money and resources towards continuing anti-obesity campaigns. It may be beneficial to market increased physical activity and better diet as a mechanism through which individuals can decrease their risk of cancer, as this may provide additional motivation to those struggling to combat obesity. The obesity epidemic is not one that can be easily solved in a laboratory. Rather, it will require continued effort by social scientists, public health professionals, politicians, corporations, and individuals to change social systems that are encouraging obesity in the United States.

These factors, though potentially difficult to modify, are modifiable and should be targeted in the future. However, the modification of the sociocultural risk factors that have been discussed is not such a straightforward task. Sociocultural barriers, including disparities in socioeconomic status, healthcare discrimination, lack of access to care, negative perceptions of cancer treatment, and fatalism, are ingrained in our society and thus remediation of such barriers will be a long-term process. Some of the largest hurdles are political, particularly regarding socioeconomic status and access to care. Thus, it will be important for the academic and scientific community to continue to educate political leaders on sociocultural issues surrounding breast cancer health in African American women so as to encourage informed decisions.

\section{Acknowledgements}

The authors thankfully acknowledge support from the National Science Foundation (1140182 to Bowser and Brown), (0956059 to Bowser and Brown), and (1060548 to Brown).

\section{References}

[1] Society AC: Global Cancer Facts and Figures: 2nd Edition. 2011. 
[2] Society AC: Cancer Facts \& Figures 2013. 2013.

[3] Society AC: Breast Cancer Facts \& Figures 2011-2012. 2012.

[4] Stark A, Kleer CG, Martin I, Awuah B, Nsiah-Asare A, Takyi V, Braman M, Quayson SE, Zarbo R, Wicha M et al: African ancestry and higher prevalence of triple-negative breast cancer: findings from an international study. Cancer 2010, 116(21):4926-4932.

[5] Pang J, Toy KA, Griffith KA, Awuah B, Quayson S, Newman LA, Kleer CG: Invasive breast carcinomas in Ghana: high frequency of high grade, basal-like histology and high EZH2 expression. Breast Cancer Res Treat 2012, 135(1):59-66.

[6] Albain KS, Unger JM, Crowley JJ, Coltman CA, Jr., Hershman DL: Racial disparities in cancer survival among randomized clinical trials patients of the Southwest Oncology Group. J Natl Cancer Inst 2009, 101(14):984-992.

[7] Griffiths CL, Olin JL: Triple negative breast cancer: a brief review of its characteristics and treatment options. Journal of pharmacy practice 2012, 25(3):319-323.

[8] Yao S, Ambrosone CB: Associations between vitamin D deficiency and risk of aggressive breast cancer in African-American women. J Steroid Biochem Mol Biol 2012.

[9] Dawood S: Triple-negative breast cancer: epidemiology and management options. Drugs 2010, 70(17):2247-2258.

[10] Boyle P: Triple-negative breast cancer: epidemiological considerations and recommendations. Ann Oncol 2012, 23 Suppl 6:vi7-12.

[11] Kwan ML, Kushi LH, Weltzien E, Maring B, Kutner SE, Fulton RS, Lee MM, Ambrosone CB, Caan BJ: Epidemiology of breast cancer subtypes in two prospective cohort studies of breast cancer survivors. Breast Cancer Res 2009, 11(3):R31.

[12] Phipps AI, Malone KE, Porter PL, Daling JR, Li CI: Reproductive and hormonal risk factors for postmenopausal luminal, HER-2-overexpressing, and triple-negative breast cancer. Cancer 2008, 113(7):1521-1526.

[13] Adisa CA, Eleweke N, Alfred AA, Campbell MJ, Sharma R, Nseyo O, Tandon V, Mukhtar R, Greninger A, Risi JD et al: Biology of breast cancer in Nigerian women: a pilot study. Ann Afr Med 2012, 11(3):169-175.

[14] Bauer KR, Brown M, Cress RD, Parise CA, Caggiano V: Descriptive analysis of estrogen receptor (ER)-negative, progesterone receptor (PR)-negative, and HER2-negative invasive breast cancer, the so-called triple-negative phenotype: a population-based study from the California cancer Registry. Cancer 2007, 109(9):1721-1728.

[15] Ma H, Wang Y, Sullivan-Halley J, Weiss L, Marchbanks PA, Spirtas R, Ursin G, Burkman RT, Simon MS, Malone KE et al: Use of four biomarkers to evaluate the risk of breast cancer subtypes in the women's contraceptive and reproductive experiences study. Cancer Res 2010, 70(2):575-587.

[16] Brewster K, Wileyto EP, Kessler L, Collier A, Weathers B, Stopfer JE, Domchek S, Halbert CH: Sociocultural predictors of breast cancer risk perceptions in African American breast cancer survivors. Cancer Epidemiol Biomarkers Prev 2007, 16(2):244-248.
[17] Coyle YM: The effect of environment on breast cancer risk. Breast Cancer Res Treat 2004, 84(3):273-288.

[18] Tseng M, Byrne C, Evers KA, Daly MB: Dietary intake and breast density in high-risk women: a cross-sectional study. Breast Cancer Res 2007, 9(5):R72.

[19] Garland CF, Gorham ED, Mohr SB, Grant WB, Giovannucci EL, Lipkin M, Newmark H, Holick MF, Garland FC: Vitamin $\mathrm{D}$ and prevention of breast cancer: pooled analysis. J Steroid Biochem Mol Biol 2007, 103(3-5):708-711.

[20] Mohr SB, Gorham ED, Alcaraz JE, Kane CI, Macera CA, Parsons JK, Wingard DL, Garland CF: Does the evidence for an inverse relationship between serum vitamin $\mathrm{D}$ status and breast cancer risk satisfy the Hill criteria? Dermatoendocrinol 2012, 4(2):152-157.

[21] Giovannucci E: Vitamin D and cancer incidence in the Harvard cohorts. Ann Epidemiol 2009, 19(2):84-88.

[22] Pirianov G, Colston KW: Interaction of vitamin D analogs with signaling pathways leading to active cell death in breast cancer cells. Steroids 2001, 66(3-5):309-318.

[23] Neuhouser ML, Sorensen B, Hollis BW, Ambs A, Ulrich CM, McTiernan A, Bernstein L, Wayne S, Gilliland F, Baumgartner $\mathrm{K}$ et al: Vitamin $\mathrm{D}$ insufficiency in a multiethnic cohort of breast cancer survivors. Am J Clin Nutr 2008, 88(1):133-139.

[24] Lewis TJ, Dupont WD, Egan KM, Jones CD, Disher AC, Riddle WR, Fair AM: The "Got D'ViBE?" study: an inter-institutional project assessing vitamin $\mathrm{D}$ and mammographic breast density. J Health Care Poor Underserved 2010, 21(1 Suppl):17-25.

[25] Bertone-Johnson ER, McTiernan A, Thomson CA, Wactawski-Wende J, Aragaki AK, Rohan TE, Vitolins MZ, Tamimi RM, Johnson KC, Lane D et al: Vitamin D and calcium supplementation and one-year change in mammographic density in the women's health initiative calcium and vitamin D trial. Cancer Epidemiol Biomarkers Prev 2012, 21(3):462-473.

[26] Rozen F, Pollak M: Inhibition of insulin-like growth factor I receptor signaling by the vitamin D analogue EB1089 in MCF-7 breast cancer cells: A role for insulin-like growth factor binding proteins. Int J Oncol 1999, 15(3):589-594.

[27] Suba Z: Light deficiency confers breast cancer risk by endocrine disorders. Recent Pat Anticancer Drug Discov 2012, 7(3):337-344.

[28] Egan KM, Signorello LB, Munro HM, Hargreaves MK, Hollis BW, Blot WJ: Vitamin D insufficiency among African-Americans in the southeastern United States: implications for cancer disparities (United States). Cancer Causes Control 2008, 19(5):527-535.

[29] Yao S, Zirpoli G, Bovbjerg DH, Jandorf L, Hong CC, Zhao H, Sucheston LE, Tang L, Roberts M, Ciupak G et al: Variants in the vitamin D pathway, serum levels of vitamin $\mathrm{D}$, and estrogen receptor negative breast cancer among African-American women: a case-control study. Breast Cancer Res 2012, 14(2):R58.

[30] Grant WB, Peiris AN: Differences in vitamin D status may account for unexplained disparities in cancer survival rates between African and white Americans. Dermatoendocrinol 2012, 4(2):85-94. 
[31] Macdonald HM: Contributions of sunlight and diet to vitamin D status. Calcif Tissue Int 2013, 92(2):163-176.

[32] Wejse C, Olesen R, Rabna P, Kaestel P, Gustafson P, Aaby P, Andersen PL, Glerup H, Sodemann M: Serum 25-hydroxyvitamin $\mathrm{D}$ in a West African population of tuberculosis patients and unmatched healthy controls. Am J Clin Nutr 2007, 86(5):1376-1383.

[33] Gerend MA, Pai M: Social determinants of Black-White disparities in breast cancer mortality: a review. Cancer Epidemiol Biomarkers Prev 2008, 17(11):2913-2923.

[34] Flegal KM, Carroll MD, Kit BK, Ogden CL: Prevalence of obesity and trends in the distribution of body mass index among US adults, 1999-2010. Jama 2012, 307(5):491-497.

[35] Garland CF, French CB, Baggerly LL, Heaney RP: Vitamin D supplement doses and serum 25-hydroxyvitamin $\mathrm{D}$ in the range associated with cancer prevention. Anticancer Res 2011, 31(2):607-611.

[36] Phipps AI, Chlebowski RT, Prentice R, McTiernan A, Wactawski-Wende J, Kuller LH, Adams-Campbell LL, Lane D, Stefanick ML, Vitolins $M$ et al: Reproductive history and oral contraceptive use in relation to risk of triple-negative breast cancer. J Natl Cancer Inst 2011, 103(6):470-477.

[37] Palmer JR, Boggs DA, Wise LA, Ambrosone CB, Adams-Campbell LL, Rosenberg L: Parity and lactation in relation to estrogen receptor negative breast cancer in African American women. Cancer Epidemiol Biomarkers Prev 2011, 20(9):1883-1891.

[38] Shinde SS, Forman MR, Kuerer HM, Yan K, Peintinger F, Hunt KK, Hortobagyi GN, Pusztai L, Symmans WF: Higher parity and shorter breastfeeding duration: association with triple-negative phenotype of breast cancer. Cancer 2010, 116(21):4933-4943.

[39] Trivers KF, Lund MJ, Porter PL, Liff JM, Flagg EW, Coates RJ, Eley JW: The epidemiology of triple-negative breast cancer, including race. Cancer Causes Control 2009, 20(7):1071-1082.

[40] Millikan RC, Newman B, Tse CK, Moorman PG, Conway K, Dressler LG, Smith LV, Labbok MH, Geradts J, Bensen JT et al: Epidemiology of basal-like breast cancer. Breast Cancer Res Treat 2008, 109(1):123-139.

[41] Bulbul NH, Ozden S, Dayicioglu V: Effects of hormone replacement therapy on mammographic findings. Arch Gynecol Obstet 2003, 268(1):5-8.

[42] Chen WY: Exogenous and endogenous hormones and breast cancer. Best Pract Res Clin Endocrinol Metab 2008, 22(4):573-585.

[43] Spector D, Mishel M, Skinner CS, Deroo LA, Vanriper M, Sandler DP: Breast cancer risk perception and lifestyle behaviors among White and Black women with a family history of the disease. Cancer Nurs 2009, 32(4):299-308.

[44] Dolle JM, Daling JR, White E, Brinton LA, Doody DR, Porter PL, Malone KE: Risk factors for triple-negative breast cancer in women under the age of 45 years. Cancer Epidemiol Biomarkers Prev 2009, 18(4):1157-1166.

[45] Gupta PB, Proia D, Cingoz O, Weremowicz J, Naber SP, Weinberg RA, Kuperwasser C: Systemic stromal effects of estrogen promote the growth of estrogen receptor-negative cancers. Cancer Res 2007, 67(5):2062-2071.

[46] Iyer V, Klebba I, McCready J, Arendt LM, Betancur-Boissel M, Wu MF, Zhang X, Lewis MT, Kuperwasser C: Estrogen promotes ER-negative tumor growth and angiogenesis through mobilization of bone marrow-derived monocytes. Cancer Res 2012, 72(11):2705-2713.

[47] Parentes-Vieira J, Lopes-Costa P, Pires C, Dos Santos A, Pereira-Filho J, da Silva B: Quantification of angiogenesis in estrogen receptor-positive and negative breast carcinoma. Int Semin Surg Oncol 2007, 4:22.

[48] Elkin M, Orgel A, Kleinman HK: An angiogenic switch in breast cancer involves estrogen and soluble vascular endothelial growth factor receptor 1. J Natl Cancer Inst 2004, 96(11):875-878.

[49] Jian J, Yang Q, Dai J, Eckard J, Axelrod D, Smith J, Huang X: Effects of iron deficiency and iron overload on angiogenesis and oxidative stress-a potential dual role for iron in breast cancer. Free Radic Biol Med 2011, 50(7):841-847.

[50] Wang CT, Chang WT, Yang TL: Study of the concentrations of calcium, copper, iron, magnesium and zinc in the hair of breast cancer patients. Trace Elements and Electrolytes 2006, 23(4):281-286.

[51] Cui Y, Vogt S, Olson N, Glass AG, Rohan TE: Levels of zinc, selenium, calcium, and iron in benign breast tissue and risk of subsequent breast cancer. Cancer Epidemiol Biomarkers Prev 2007, 16(8):1682-1685.

[52] Miller LD, Coffman LG, Chou JW, Black MA, Bergh J, D'Agostino R, Jr., Torti SV, Torti FM: An iron regulatory gene signature predicts outcome in breast cancer. Cancer Res 2011, 71(21):6728-6737.

[53] Benbrahim-Tallaa L, Tokar EJ, Diwan BA, Dill AL, Coppin JF, Waalkes MP: Cadmium malignantly transforms normal human breast epithelial cells into a basal-like phenotype. Environ Health Perspect 2009, 117(12):1847-1852.

[54] Gallagher CM, Chen JJ, Kovach JS: Environmental cadmium and breast cancer risk. Aging (Albany NY) 2010, 2(11):804-814.

[55] Julin B, Wolk A, Bergkvist L, Bottai M, Akesson A: Dietary cadmium exposure and risk of postmenopausal breast cancer: a population-based prospective cohort study. Cancer Res 2012, 72(6):1459-1466.

[56] McElroy JA, Shafer MM, Trentham-Dietz A, Hampton JM, Newcomb PA: Cadmium exposure and breast cancer risk. J Natl Cancer Inst 2006, 98(12):869-873.

[57] Pasha Q, Malik SA, Iqbal J, Shaheen N, Shah MH: Screening of trace metals in the plasma of breast cancer patients in comparison with a healthy population. Human and Ecological Risk Assessment 2009, 15:1016-1032.

[58] Saleh F, Behbehani A, Asfar S, Khan I, Ibrahim G: Abnormal blood levels of trace elements and metals, DNA damage, and breast cancer in the state of Kuwait. Biol Trace Elem Res 2011, 141(1-3):96-109.

[59] Stawarz R, Formicki G, Zakrzewiski M, Rys J, Rozmus M: Distribution of heavy metals and trace elements in human breast cancer tissues and in adjacent normal tissues of women in Poland. Fresenius Environmental Bulletin 2009, 18(2):182-188 
[60] Adams SV, Passarelli MN, Newcomb PA: Cadmium exposure and cancer mortality in the Third National Health and Nutrition Examination Survey cohort. Occup Environ Med 2012, 69(2):153-156.

[61] Egwuogu H, Shendell DG, Okosun IS, Goodfellow L: The effect of urinary cadmium on cardiovascular fitness as measured by VO2 max in white, black and Mexican Americans. Environ Res 2009, 109(3):292-300.

[62] Zhai H, Chen X, Hu Z: Study on the relationship between intake of trace elements and breast cancer mortality with chemometric methods. Comput Biol Chem 2003, 27(6):581-586.

[63] Yang CY, Chiu HF, Cheng MF, Hsu TY, Cheng MF, Wu TN: Calcium and magnesium in drinking water and the risk of death from breast cancer. J Toxicol Environ Health A 2000, 60(4):231-241.

[64] 64. Barcellos-Hoff MH: New biological insights on the link between radiation exposure and breast cancer risk. J Mammary Gland Biol Neoplasia 2013, 18(1):3-13.

[65] Lin NU, Vanderplas A, Hughes ME, Theriault RL, Edge SB, Wong YN, Blayney DW, Niland JC, Winer EP, Weeks JC: Clinicopathologic features, patterns of recurrence, and survival among women with triple-negative breast cancer in the National Comprehensive Cancer Network. Cancer 2012, 118(22):5463-5472.

[66] Vona-Davis L, Rose DP: The influence of socioeconomic disparities on breast cancer tumor biology and prognosis: a review. J Womens Health (Larchmt) 2009, 18(6):883-893.

[67] Kabat GC, Kim M, Phipps AI, Li CI, Messina CR, Wactawski-Wende J, Kuller L, Simon MS, Yasmeen S, Wassertheil-Smoller $\mathrm{S}$ et al: Smoking and alcohol consumption in relation to risk of triple-negative breast cancer in a cohort of postmenopausal women. Cancer Causes Control 2011, 22(5):775-783.

[68] Sellers TA, Vierkant RA, Cerhan JR, Gapstur SM, Vachon CM, Olson JE, Pankratz VS, Kushi LH, Folsom AR: Interaction of dietary folate intake, alcohol, and risk of hormone receptor-defined breast cancer in a prospective study of postmenopausal women. Cancer Epidemiol Biomarkers Prev 2002, 11(10 Pt 1):1104-1107.

[69] Brawley OW: Is race really a negative prognostic factor for cancer? J Natl Cancer Inst 2009, 101(14):970-971.

[70] Chu QD, Henderson AE, Ampil F, Li BD: Outcome for patients with triple-negative breast cancer is not dependent on race/ethnicity. Int J Breast Cancer 2012, 2012:764570.

[71] DeSantis C, Jemal A, Ward E: Disparities in breast cancer prognostic factors by race, insurance status, and education. Cancer Causes Control 2010, 21(9):1445-1450.

[72] Dunn BK, Agurs-Collins T, Browne D, Lubet R, Johnson KA: Health disparities in breast cancer: biology meets socioeconomic status. Breast Cancer Res Treat 2010, 121(2):281-292.

[73] Gordon NH: Association of education and income with estrogen receptor status in primary breast cancer. Am J Epidemiol 1995, 142(8):796-803.

[74] Thomson CS, Hole DJ, Twelves CJ, Brewster DH, Black RJ: Prognostic factors in women with breast cancer: distribution by socioeconomic status and effect on differences in survival. J Epidemiol Community Health 2001, 55(5):308-315.

[75] Mukhtar RA, Moore AP, Nseyo O, Baehner FL, Au A, Moore DH, Twomey P, Campbell MJ, Esserman LJ: Elevated $\mathrm{PCNA}+$ tumor-associated macrophages in breast cancer are associated with early recurrence and non-Caucasian ethnicity. Breast Cancer Res Treat 2011, 130(2):635-644.

[76] Avis-Williams A, Khoury A, Lisovicz N, Graham-Kresge S: Knowledge, attitudes, and practices of underserved women in the rural South toward breast cancer prevention and detection. Fam Community Health 2009, 32(3):238-246.

[77] Fair AM, Monahan PO, Russell K, Zhao Q, Champion VL: The interaction of perceived risk and benefits and the relationship to predicting mammography adherence in African American women. Oncol Nurs Forum 2012, 39(1):53-60.

[78] West DS, Greene PG, Kratt PP, Pulley L, Weiss HL, Siegfried $\mathrm{N}$, Gore SA: The impact of a family history of breast cancer on screening practices and attitudes in low-income, rural, African American women. J Womens Health (Larchmt) 2003, 12(8):779-787.

[79] Masi CM, Gehlert S: Perceptions of breast cancer treatment among African-American women and men: implications for interventions. J Gen Intern Med 2009, 24(3):408-414.

[80] Haggstrom DA, Schapira MM: Black-white differences in risk perceptions of breast cancer survival and screening mammography benefit. J Gen Intern Med 2006, 21(4):371-377.

[81] Hall AG, Khoury AJ, Lopez ED, Lisovicz N, Avis-Williams A, Mitra A: Breast cancer fatalism: the role of women's perceptions of the health care system. J Health Care Poor Underserved 2008, 19(4):1321-1335.

[82] Spurlock WR, Cullins LS: Cancer fatalism and breast cancer screening in African American women. Abnf J 2006, 17(1):38-43.

[83] Quach T, Nuru-Jeter A, Morris P, Allen L, Shema SJ, Winters JK, Le GM, Gomez SL: Experiences and perceptions of medical discrimination among a multiethnic sample of breast cancer patients in the Greater San Francisco Bay Area, California. Am J Public Health 2012, 102(5):1027-1034.

[84] Song L, Hamilton JB, Moore AD: Patient-healthcare provider communication: perspectives of African American cancer patients. Health Psychol 2012, 31(5):539-547. 